\title{
Bacteria-Mediated Synthesis of Silver and Silver Chloride Nanoparticles and Their Antimicrobial Activity
}

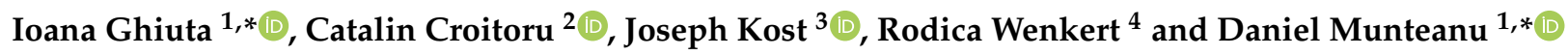 \\ 1 Materials Science Department, Transilvania University of Brasov, 29 Eroilor Blvd., \\ 500036 Brasov, Romania \\ 2 Materials Engineering and Welding Department, Transilvania University of Brasov, 29 Eroilor Blvd., \\ 500036 Brasov, Romania; c.croitoru@unitbv.ro \\ 3 Department of Chemical Engineering, Ben-Gurion University of the Negev, P.O.B 653, \\ Beer-Sheva 84105, Israel; kost@bgu.ac.il \\ 4 Clinical Microbiology Laboratory, Soroka University Medical Center, Beer-Sheva 84101, Israel; \\ RodicaWe@clalit.org.il \\ * Correspondence: ioana.ghiuta@unitbv.ro (I.G.); danielmunteanu@unitbv.ro (D.M.); \\ Tel.: +40-734219708 (I.G.); +40-745750782 (D.M.)
}

check for updates

Citation: Ghiuta, I.; Croitoru, C.; Kost, J.; Wenkert, R.; Munteanu, D. Bacteria-Mediated Synthesis of Silver and Silver Chloride Nanoparticles and Their Antimicrobial Activity. Appl. Sci. 2021, 11, 3134. https:// doi.org/10.3390/app11073134

Academic Editor: Won Ho Park

Received: 11 March 2021

Accepted: 25 March 2021

Published: 1 April 2021

Publisher's Note: MDPI stays neutral with regard to jurisdictional claims in published maps and institutional affiliations.

Copyright: (c) 2021 by the authors. Licensee MDPI, Basel, Switzerland. This article is an open access article distributed under the terms and conditions of the Creative Commons Attribution (CC BY) license (https:// creativecommons.org/licenses/by/ $4.0 /)$.

\begin{abstract}
Within the frame of this work, the synthesis of silver nanoparticles (Ag NPs) and silver chloride nanoparticles ( $\mathrm{AgCl} \mathrm{NPs}$ ) as mediated by microbes has been investigated. The nanoparticles were reduced from a silver nitrate precursor by the presence of bacteria, like Raoultella planticola and Pantoea agglomerans. The results show that the characteristic surface plasmon resonance absorption band occurs at about $440 \mathrm{~nm}$. Nanoparticles were also characterized with the help of scanning electron microscopy (SEM), energy dispersive spectroscopy (EDS), transmission electron microscopy (TEM), and X-ray diffraction (XRD), which showed the formation of spherical Ag/AgCl NPs with a centered cubic crystal structure and a mean particle size of around $10-50 \mathrm{~nm}$. Assays for antimicrobial activity of the biosynthesized nanoparticles demonstrated meaningful results against microorganisms such as Staphylococcus aureus, Streptococcus pyogenes, Salmonella, and Bacillus amyloliquefaciens. Furthermore, this study shows that the combination of the obtained nanoparticles with standard antibiotics may be useful in the fight against emerging microbial drug resistance.
\end{abstract}

Keywords: silver chloride; nanoparticles; Pantoea agglomerans; Raoultella planticola; antibacterial properties

\section{Introduction}

In the last few years, the interest in obtaining nanoscale particles through eco-friendly and low-cost methods has considerably increased due to their attractive properties, excellent biocompatibility, and high antimicrobial activity [1-3]. It has been reported that nanoparticles (NPs) synthesized by microorganisms have enhanced microbiological reaction rates than nanoparticles obtained through chemical methods $[2,4]$. Although the biological synthesis methods of nanoparticles have been used mainly for biomedical and bioprocess applications, other improvements in nanoparticle properties have been investigated. For example, bio-synthesized magnetite nanoparticles have exhibited higher coercivity and less remanence than their chemically synthesized counterparts [3].

Green synthesis methods involving plants, algae, bacteria, fungi, actinomycetes yeasts, and viruses represent an advancement over other methods because they are simple, able to be reproduced at low-cost, and usually result in high material stability [1,5]. The abovementioned organisms contain proteins that act as reducing and capping agents to form stable and shape-controlled nanoparticles [6]. Silver nanoparticles synthesized by different Gram-negative bacteria were found to be stable for up to 3 months while showing significant antimicrobial activity [7]. Ahmed and co-workers stated that silver nanoparticles (Ag NPs) green-synthesized by F. oxysporum had excellent stability even after 4 months when kept under $4^{\circ} \mathrm{C}$ cooling conditions, with the peak of surface plasmon resonance 
remaining unchanged [8]. Furthermore, Ag NPs synthesized by psychrophilic bacteria have also been found to be stable in terms of shape even after 8 months of being kept in the dark [9]. Also, the fact that green synthesis does not involve chemical agents associated with environmental toxicity represents another advantage over conventional methods. It has been found that $\mathrm{Ag} / \mathrm{AgCl} \mathrm{NPs}$ possess substantial antibacterial and antifungal properties [10-12]. Da Silva Ferreira and co-workers considered the use of biosynthesized $\mathrm{AgCl} \mathrm{NPs} \mathrm{in} \mathrm{textiles,} \mathrm{food} \mathrm{packaging,} \mathrm{and} \mathrm{surgical} \mathrm{equipment} \mathrm{applications} \mathrm{[13].} \mathrm{This}$ relies on the potent bacterial toxicity exhibited by nanoparticles towards Gram-positive and Gram-negative pathogens [13,14]. Likewise, silver and silver chloride nanoparticles obtained through green synthesis methods mediated by plants showed significant antimicrobial activity toward several pathogenic bacteria and fungi [12]. Silver is one of the most researched materials at the nanoscale level, among other noble metals like gold or palladium. The unique properties of Ag NPs open new gates for applications in fields such as medicine, pharmacy, sensors, catalysis, and electronic devices [15-17]. As a result of their demand in wound therapeutic outcomes, long-term water storage, and antimicrobial agents in deodorants, silver chloride nanoparticles represent one of the most researched systems among associated silver-containing materials [4,18].

A multitude of approaches have been employed in the synthesis of silver and silver chloride nanoparticles of different configurations. Laser ablation, chemical reduction, microwave processing, and thermal decomposition are just a few examples [19]. Besides these, the use of biosynthetic methods for nanoparticle synthesis has been suggested, with reducing and stabilizing agents of natural origin. These agents (enzymes, extractives, and so forth) directly influence the monodispersity, size, and shape of the obtained particles [10].

Free radical scavenging molecules are found in large amounts in the majority of plants, most commonly as phenolic and nitrogen compounds, vitamins, reducing sugars, terpenoids and other metabolites that are known to have great antioxidant activity. Polyols and antioxidants are the main compounds that are well-known in the plants used for nanoparticle synthetization. In the process of nanoparticles synthetization, hydroxyl and carboxylic groups can act as reducing agents and help with stability. [20]. Furthermore, it has been shown that reducing agents, like enzymes (for example, NADH-dependent reductase, carboxylate groups, amylase, etc.), are mainly responsible for inorganic metallic nanoparticle formation [20].

Nelson Duran demonstrated that the sulfhydryl group produced by the semi-purified laccase enzyme secreted by Trametes versicolor plays a vital role as a reducing agent in the synthesis of $\mathrm{Ag} / \mathrm{AgCl}$ NPs [21]. In this framework, a green method of nanoparticle synthesis was mediated by a marine alga, namely Sargassum plagiophyllu [22]. Following the biological pathway, Eugenio and co-authors reported on the yeast-assisted synthesis of $\mathrm{Ag} / \mathrm{AgCl}$ NPs. Reduction took place in the presence of yeast obtained from the gut of termites (Cornitermes cumulans) [23]. Patil and collaborators reported that Agrimonia pilosa extract-mediated $\mathrm{Ag} / \mathrm{AgCl}$ NPs had antibacterial activity against Listeria monocytogenes, Staphylococcus aureus, Staphylococcus saprophyticus and Pseudomonas putida pathogens [24]. Bacillus subtilis and Penicillium species have been reported to possess the ability to reduce silver chloride nanoparticles, with a possible application in antimicrobial activity $[25,26]$. $\mathrm{AgCl}$ nanoparticles synthesis in the three-dimensional non-woven network of nanoporous bacterial cellulose has also been successful and exhibited high hydrophilic properties [14].

In the present study, silver and silver chloride nanoparticles were obtained by using two different Gram-negative bacteria of the family Enterobacteriaceae: Pantoea and Raoultella. Bacteria from these genera have been found to reduce $\mathrm{AgNO}_{3}$ into $\mathrm{Ag} / \mathrm{AgCl}$ NPs without using any stabilizing or capping agent. Also, we have previously shown that biosynthesized silver chloride nanoparticles can exert an antimicrobial inhibitory effect against various microorganisms, such as Staphylococcus aureus, Streptococcus pyogenes, Salmonella, or Bacillus amyloliquefaciens [27,28]. 


\section{Materials and Methods}

\subsection{Types of Microorganisms and Conditions for Bacterial Culture}

Pantoea and Raoultella planticola bacterial strains were provided by the Soroka University Medical Center in Beersheva, Israel. The microorganisms were cultured in a solid medium, namely Sabouraud agar (Scharlau Chemicals), and incubated at $33^{\circ} \mathrm{C}$ for $48 \mathrm{~h}$.

\subsection{Bio-Reducing of Silver and Silver Chloride Nanoparticles Using Pantoea Agglomerans and Raoultella Planticola}

The synthesis process of $\mathrm{Ag}$ and $\mathrm{AgCl}$ nanoparticles begins by growing $1 \mu \mathrm{L}$ of each bacterial strain type in Erlenmeyer flasks containing $45 \mathrm{~mL}$ of liquid medium (Sigma Aldrich Infusion Brain-Cord, St. Louis, MO, USA). According to the composition of the growth media, the bacteria were evolved in beef heart (infusion from $250 \mathrm{~g}$ ), $5 \mathrm{~g} / \mathrm{L}$; calf brains (infusion from $200 \mathrm{~g}$ ), $12.5 \mathrm{~g} / \mathrm{L}$; disodium hydrogen phosphate, $2.5 \mathrm{~g} / \mathrm{L} ; \mathrm{D}(+)$-glucose, $2 \mathrm{~g} / \mathrm{L}$; peptone, $10 \mathrm{~g} / \mathrm{L}$; and sodium chloride, $5 \mathrm{~g} / \mathrm{L}$. The cultures were incubated in a rotating incubator at $33^{\circ} \mathrm{C}$ for $24 \mathrm{~h}$ under $150 \mathrm{rpm}$ magnetic stirring. For the separation of the biomass from the supernatant, the cultures were centrifuged at $4000 \mathrm{rpm}$ for $30 \mathrm{~min}$. Afterwards, the cell-free culture supernatant was separated from the bacterial culture broth, and $5 \mathrm{~mL}$ of the suspensions from both bacteria were added to $45 \mathrm{~mL}$ of precursor solution $(1 \mathrm{mM} \mathrm{AgNO}$ ). The samples were kept in an incubator for $48 \mathrm{~h}$ at $33^{\circ} \mathrm{C}$ with $150 \mathrm{rpm}$ stirring.

\subsection{Morphostructural Characterization of $\mathrm{Ag}$ and $\mathrm{AgCl}$ Nanoparticles}

The UV-visible absorption spectra of the colloidal nanoparticle systems were measured using a Jasco V-630 spectrophotometer. The spectra were scanned in the wavelength interval between 200 and $600 \mathrm{~nm}$, with a wavelength scanning step of $1.5 \mathrm{~nm}$.

The crystal geometry of the silver chloride nanoparticles was analyzed using a Philips PW 1050/70 XRD powder diffractometer with a graphite monochromator using CuK $\alpha 1$ radiation $(\lambda=1.54 \AA)$. The employed voltage was $40 \mathrm{kV}$, the current was $28 \mathrm{~mA}$, and the scanning range was $10 \div 80^{\circ}$ (Bragg-Brentano geometry).

Transmission electron microscopy (TEM) and selected area electron diffraction (SAED) analyses were performed with a Tecnai 12 Twin (FEI) microscope operating at $100 \mathrm{kV}$. This microscope is equipped with a fully computerized goniometer (with \pm 60 degrees of elasticity inclination) and two charge-coupled devices (CCD) MultiScan cameras (Gatan 791 and wide angle Gatan 794), allowing high quality images to be recorded.

Sample preparation for TEM involved placing a drop of colloidal solution containing silver chloride nanoparticles on a $3 \mathrm{~mm}$ carbon-coated copper screen specific for TEM analysis. The samples were then allowed to evaporate. Surface areas were previously cut using a plasma-cleaner from Harrick Plasma.

A scanning electron microscope (SEM; JSM 7400f) with an energy dispersion spectroscopy (EDS) platform was used to examine the morphological characteristics and chemical composition of the nanoparticles. The silver chloride nanoparticle colloid placed on the copper screen from the TEM analysis was sprayed with a thin layer of platinum to ensure better conductivity. Afterwards, the samples were mounted on double-sided carbon tape. The acceleration voltage was fixed at $10 \mathrm{kV}$. A thin platinum layer was deposited on the specimens, consisting of two spraying sessions of $10 \mathrm{~s}$ each for the purpose of avoiding charging them.

To obtain additional information on the morphology and size of the biosynthetic nanoparticles, an MFP-3D-BIO atomic force microscope was used. Samples of silver chloride nanoparticles reduced by R. planticola and P. agglomerans were subjected to centrifugation at $2000 \mathrm{rpm}$ for $10 \mathrm{~min}$ and the obtained material was washed with deionized water to remove any possible biomass contamination. The pellet was resuspended in a small amount of deionized water by ultrasonication, after which it was added dropwise to a Si substrate, then allowed to dry. The samples were analyzed using the Atomic Force Microscope (AFM) non-contact mode. Height data were collected at a scanning frequency of $2.4 \mathrm{~Hz}$. The biosynthetic silver nanoparticles were scanned using AFM to understand 
the exact configuration of the biosynthesized nanoparticles, particularly to verify that silver nanoparticles were more or less homogeneous in size and had a spherical shape.

\subsection{Antibacterial Activity of $\mathrm{Ag} / \mathrm{AgCl} \mathrm{NPS}$}

To test the antimicrobial activity of the nanoparticles, four bacterial strains were selected and grown in solid media as set out in our previous paper [28]. In this assay, $1 \mu \mathrm{L}$ of each culture was suspended in $3 \mathrm{~mL} \mathrm{NaCl}$.

The antibacterial activity of silver and silver chloride nanoparticles was evaluated against four bacteria, namely Staphylococcus aureus, Streptococcus pyogenes, Salmonella, and Bacillus amyloliquefaciens. The antimicrobial potential of silver and silver chloride nanoparticles was tested through the disc diffusion method. This method is described in the Clinical and Laboratory Standards Institute (CLSI) M02-A11 standard and consists of impregnating $15 \mu \mathrm{L}$ of solution containing $\mathrm{Ag} / \mathrm{AgCl}$ NPs on a $6 \mathrm{~mm}$ diameter disc made from Whatman glass microfiber filters. Additionally, the synergistic response of silver and silver chloride nanoparticles in combination with commercial antibiotics against selected bacteria was tested, using $6 \mathrm{~mm}$ disks with $5 \mu \mathrm{g}$ ciprofloxacin (CIP 5), $30 \mu \mathrm{g}$ vancomycin (VA 30), and $15 \mu \mathrm{g}$ erythromycin (E 15), each additionally impregnated with a solution of $15 \mu \mathrm{L}$ of $\mathrm{Ag} / \mathrm{AgCl} \mathrm{NPs}$. The samples were prepared in triplicate and incubated at $33^{\circ} \mathrm{C}$. After $24 \mathrm{~h}$, the inhibition diameter zone was measured and compared with the control samples consisting of discs with $5 \mu \mathrm{g}$ ciprofloxacin, $30 \mu \mathrm{g}$ vancomycin and $15 \mu \mathrm{g}$ erythromycin.

The fold increase was calculated with the formula [28]:

$$
\frac{b-a}{a} \times 100[\%]
$$

where a represents the diameter of the inhibition zone for the antibiotic disc, and $\mathrm{b}$ represents the diameter of the inhibition zone for the combination of $\mathrm{Ag} / \mathrm{AgCl} \mathrm{NPs}+$ antibiotic.

Microbial inhibition zones were measured with a digital caliper. The results were expressed as the mean and standard deviation of three independent experiments.

\section{Results and Discussion}

The extracts from Pantoea and Raoultella bacteria were able to reduce $\mathrm{Ag}^{+}$to $\mathrm{Ag}^{\circ}$ in an aqueous environment at basic $\mathrm{pH}$ after an incubating period of $48 \mathrm{~h}$ at $33^{\circ} \mathrm{C}$. According to Ovais and co-workers, microbial cells secrete enzymes (reductases) that reduce metal ions to the metallic state, enabling the formation of nanoparticles [29]. During the centrifugation process, the bacterial cells were separated from the enzymatic extracts (cell-free culture supernatant). The supernatant was then used in further experiments in our research. The reaction was followed by a color change of the colloids containing the supernatant and the aqueous $\mathrm{AgNO}_{3}$ from light yellow to brownish, suggesting the formation of NPs [30]. The appearance of the brownish color occurs due to surface plasmon resonance phenomena, which are characteristic of silver and silver chloride nanoparticles [23,31]. The color of the control samples ( $1 \mathrm{mM} \mathrm{AgNO}_{3}+$ liquid media used for growing bacteria) remained unchanged. The difference between the samples can be observed in Figure 1A.

Figure $1 \mathrm{~B}$ presents the visible UV absorption spectra of solutions containing $\mathrm{Ag} / \mathrm{AgCl}$ NPs obtained using the Pantoea and Raoultella bacterial extracts. The spectra of the nanoparticles obtained due to the bioreduction activity of both bacterial extracts, $R$. planticola and P. agglomerans, showed absorption peaks at $443 \mathrm{~nm}$ and $438 \mathrm{~nm}$, respectively, which are specific for silver and silver chloride nanoparticles.

Pure silver nanoparticles exhibit a typical plasmon resonance absorption band between $\sim 400-500 \mathrm{~nm}$, while pure silver chloride nanoparticles exhibited an UV absorption band at approximately $250 \mathrm{~nm}$. The reports confirmed that peaks of approximately $440 \mathrm{~nm}$ coincided with the plasmon resonance of silver nanoparticles combined with silver chloride nanoparticles $[11,24]$. Since there is only one peak for each solution, we can associate the results with the spherical shape of the nanoparticles. The morphologies of nanoparticles help serve their various purposes, including antimicrobial activity applications. The shape 
of the nanoparticles dictates their application in therapeutical applications, such as particle adhesion, cell internalization, and distribution [32].
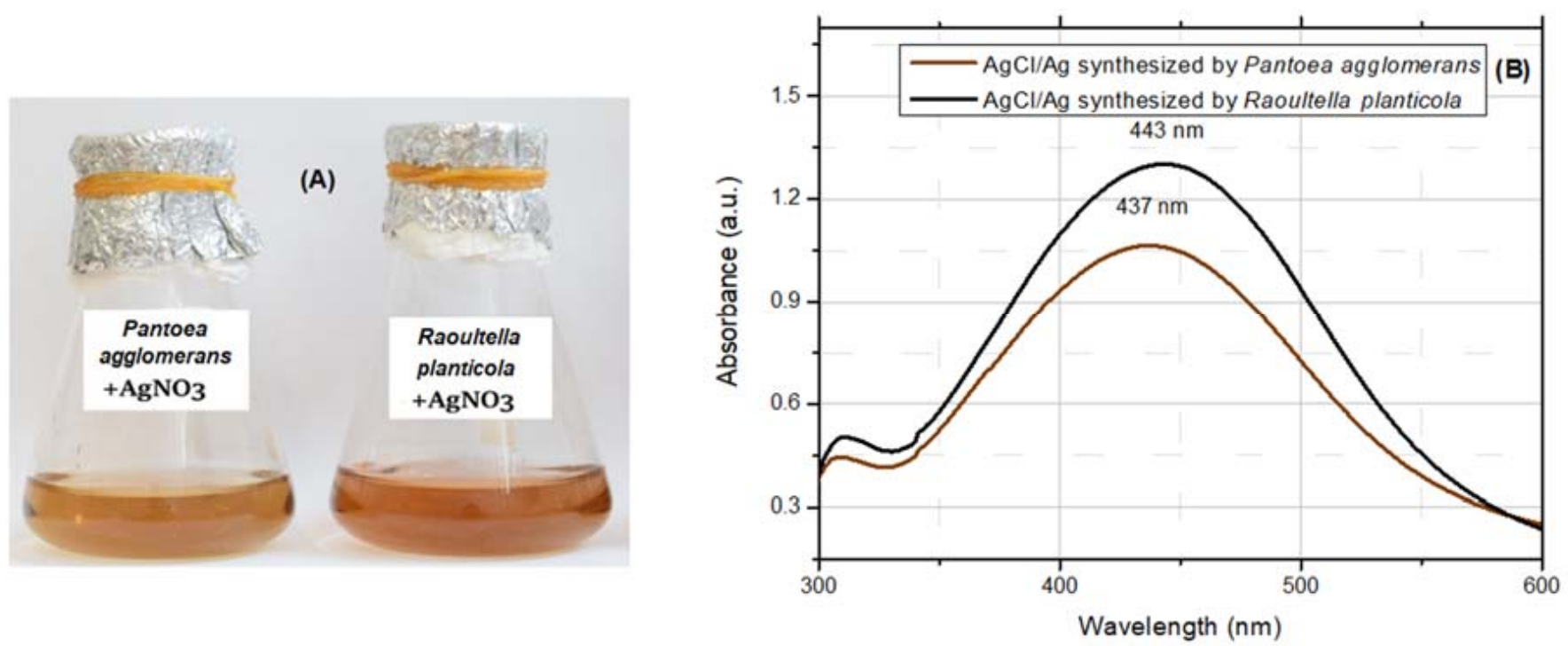

Figure 1. (A) Colloids with Ag/ $\mathrm{AgCl}$ nanoparticles (NPs); (B) UV-visible spectra of colloids with Ag/AgCl nanoparticles, biosynthesized by Raoultella planticola and Pantoea agglomerans.

As reported, the position and number of spectral absorption peaks provide useful information about the shape and size of nanoparticles [33]. Surface plasmon resonance also depends on the traits of the chemical environment, namely the adsorbed species on the surface of the nanoparticles and the dielectric constant [34]. One of the effects of the collective oscillation of free electrons on the metallic particle surface is the strong surface plasmon resonance ability of silver nanoparticles. Particle size is the main factor for these oscillations and is also an important factor that helps in determining the specific wavelength range of the absorption in the visible spectrum [35]. In the colloid, the spherical shape and uniform distribution of $\mathrm{Ag} / \mathrm{AgCl}$ nanoparticles are determined by the symmetrical shape of the SPR peak. A change in color has been determined in the solution from light yellow to brownish, indicating that $\mathrm{Ag} / \mathrm{AgCl}$ nanoparticles induced SPR phenomena. With the help of XRD and SAED techniques, we were able to observe both the interaction and the difference between specific phases of the biosynthesized Ag/ AgCl NPs [10].

The crystalline structure was established by the diffraction peaks shown in Figure 2, which match (according to the file standard 01-071-5209) to the crystallographic planes (111), (200), (220), (311), (222), and (440) specific to the face-centered cubic unit cell of the $\mathrm{AgCl}$ crystal [30].

The presence of concentric rings and diffraction dots as seen in the SAED patterns supports the fact that the nature of the $\mathrm{AgCl}$ and $\mathrm{Ag}$ nanoparticles is crystalline, as shown in Figure 3B [34]. At the same time, the interplanar distances present in the diffraction patterns correspond to the indexing of face-centered cubic unit cells of silver and silver chloride crystals. It can be seen that the predominant crystallographic growth planes are (111), (200), (220), (311), (222), (400) and (420) for AgCl NPs, due to a larger number of brighter points in their structure. Diffraction planes corresponding to the Ag crystals found most commonly in the nanoparticles synthesized using microorganisms are (111) and (220), according to the 00-004-0783 XRD standard. By increasing the $\mathrm{NaCl}$ concentration, the presence of silver crystals could be suppressed, forming the desired $\mathrm{AgCl}$ configuration [36]. 


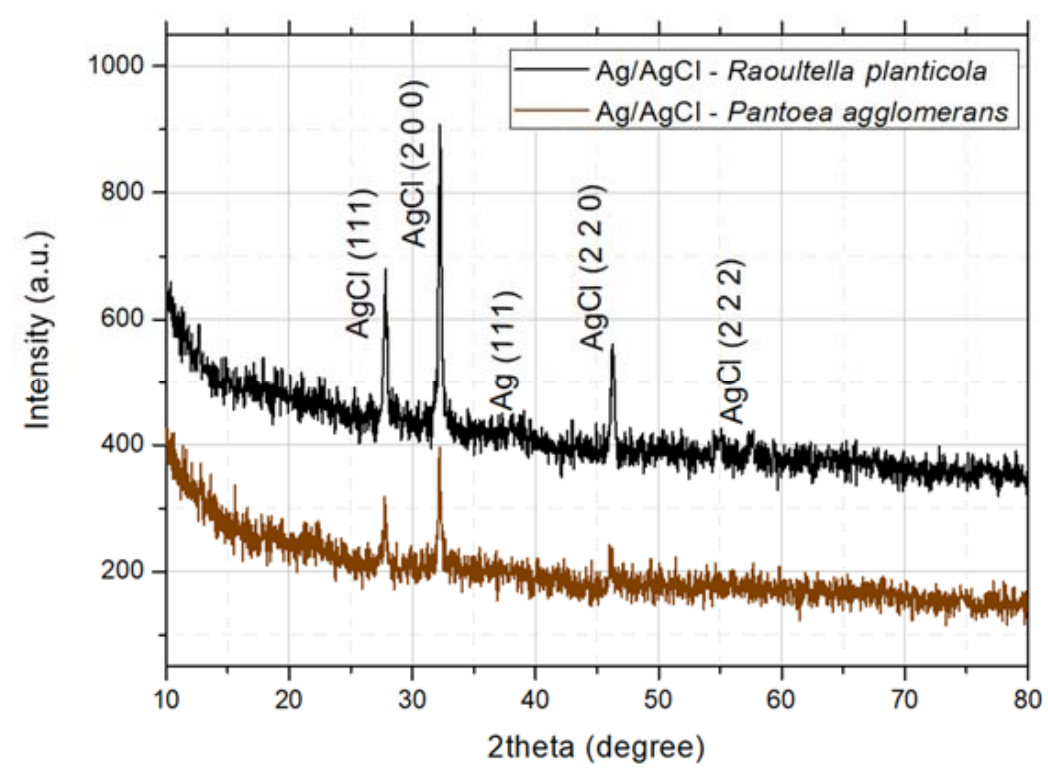

Figure 2. X-ray diffraction (XRD) patterns for $\mathrm{Ag} / \mathrm{AgCl}$ nanoparticles biosynthesized by Gramnegative bacteria from the Enterobacteriaceae family.

\section{A}
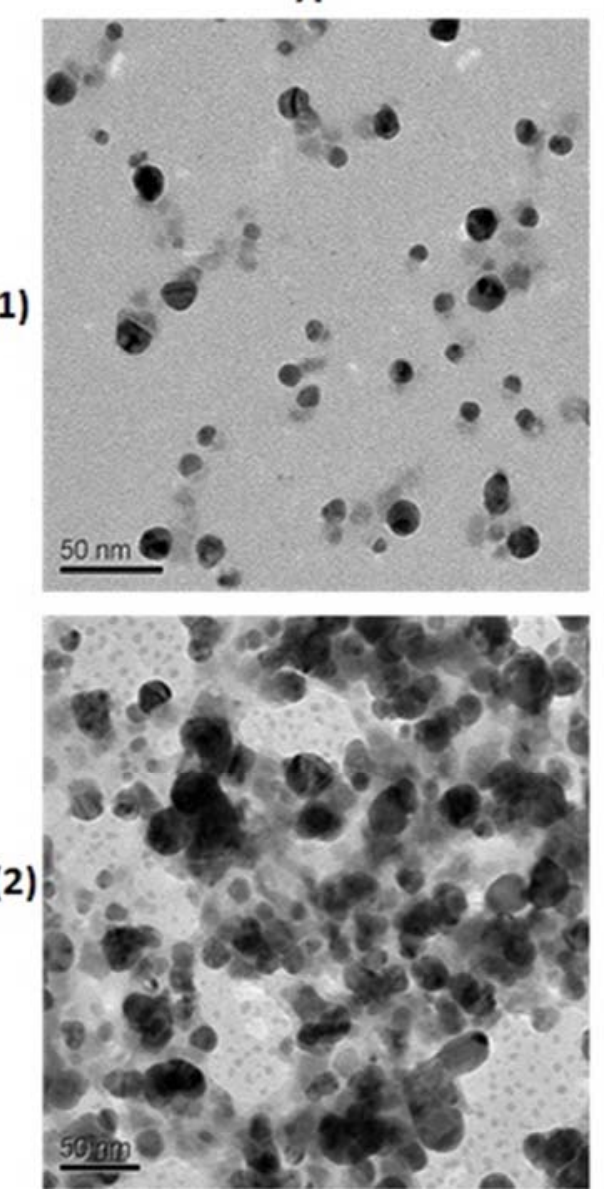

B
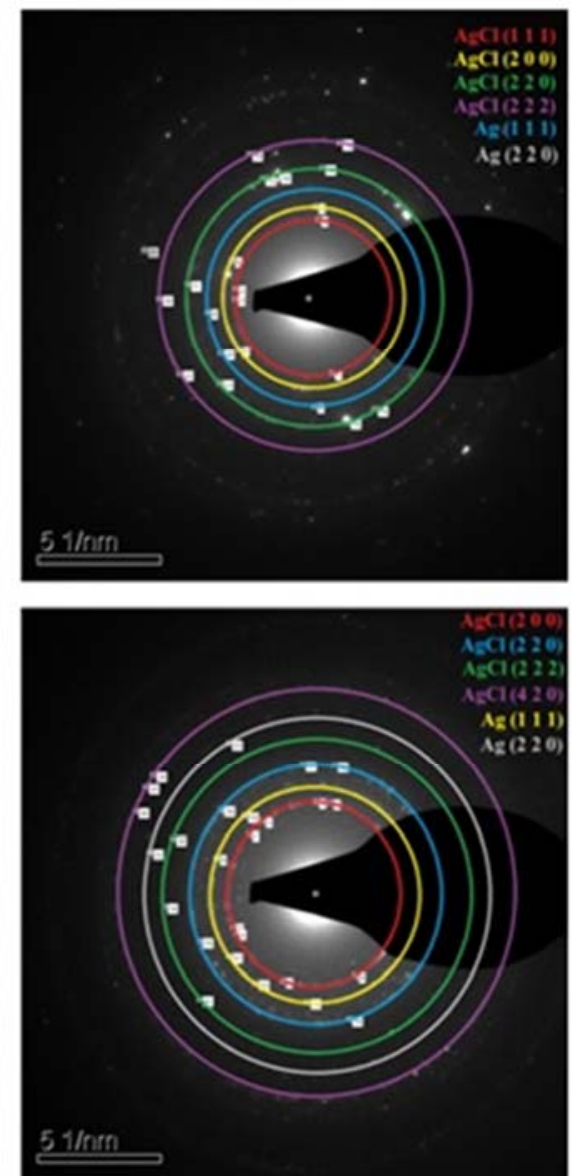

Figure 3. (A) Transmission electron microscopy (TEM) images of silver chloride nanoparticles (scale bar: $50 \mathrm{~nm}$ ) and (B) selected area electron diffraction (SAED) pattern of $\mathrm{Ag} / \mathrm{AgCl}$ nanoparticles biosynthesized by (1) Raoultella planticola and (2) Pantoea agglomerans. 
$\mathrm{Ag} / \mathrm{AgCl}$ NPs synthesized using Raoultella bacteria were smaller (in the 10-30 nm range according to TEM analysis) (Figure 3A-1). Pantoea bacteria mediated the synthesis of silver chloride nanoparticles of a wider size range; their spherical shape and dimensions reached up to $50 \mathrm{~nm}$ and can be observed in Figure 3A-2. SEM analysis (Figure 4A) confirmed the formation of spherical nanoparticles. The SEM microscopy images suggest that the diameter of the silver chloride nanoparticles ranges from 10-50 nm.

A

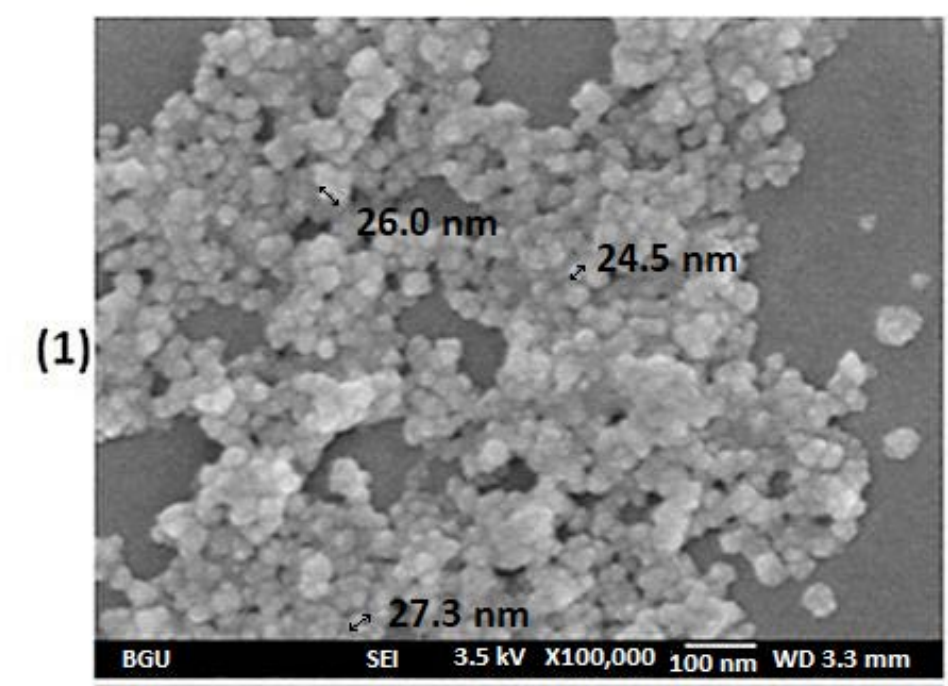

(2)

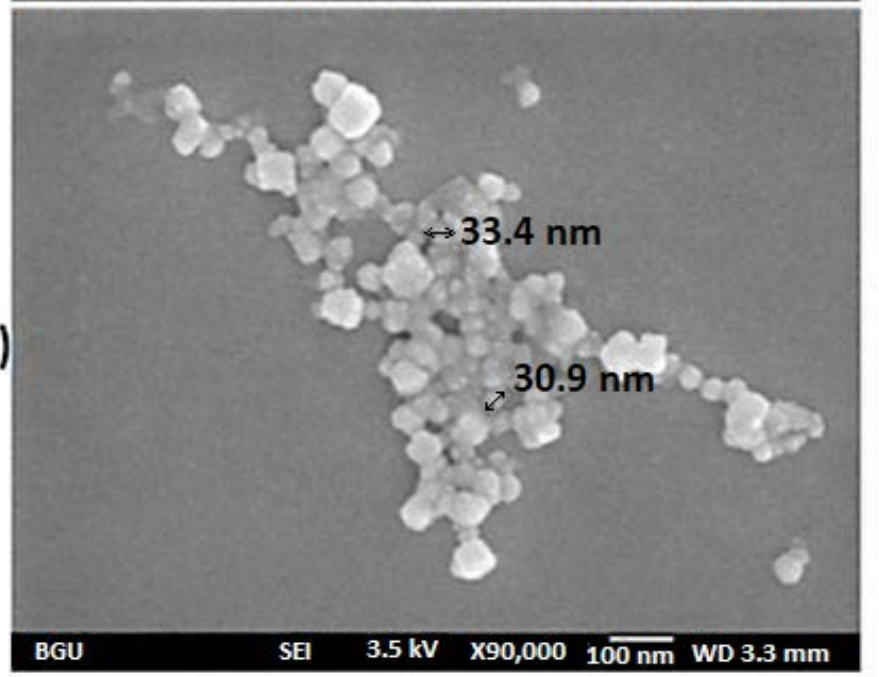

B
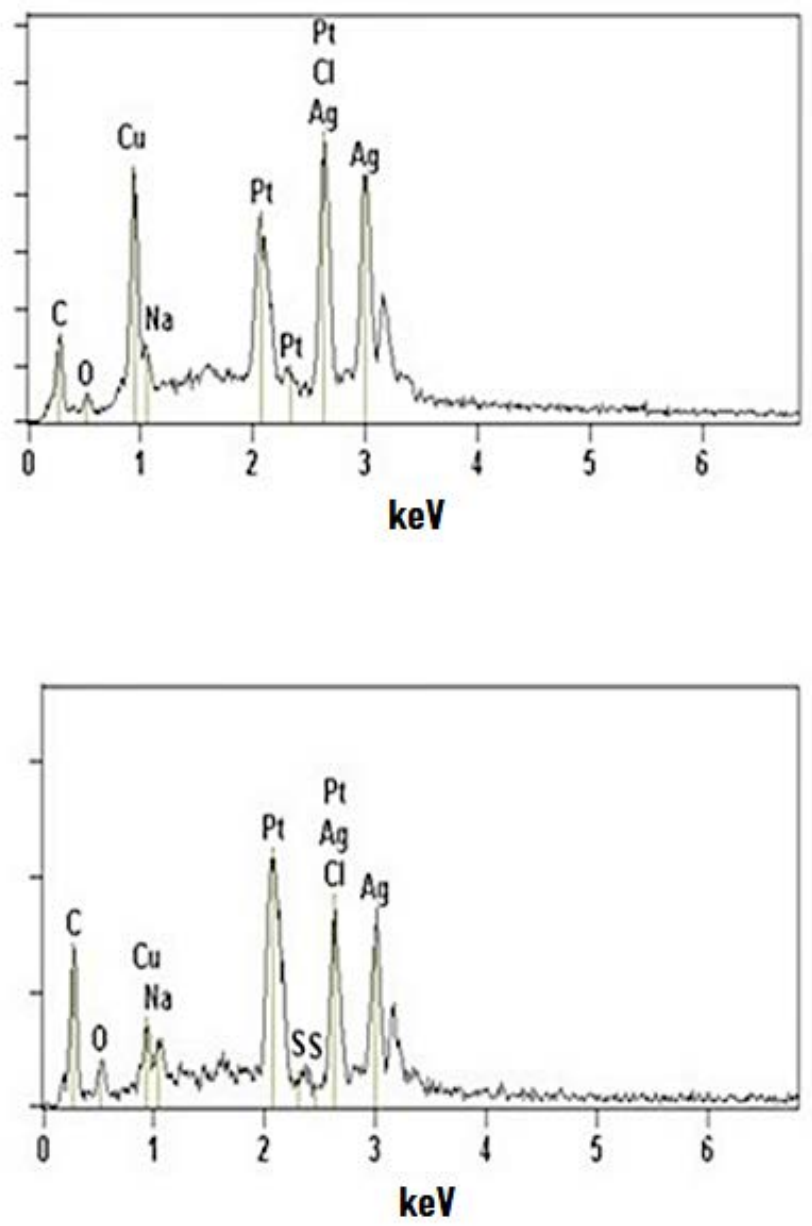

Figure 4. Scanning electron microscopy (SEM) images (A) and energy dispersive spectroscopy (EDS) spectra (B) of $\mathrm{Ag} / \mathrm{AgCl}$ NPs nanoparticles biosynthesized in the presence of (1) Raoultella and (2) Pantoea extracts.

The EDS spectra (Figure 4B) indicate the existence of the main elements, specifically $\mathrm{Ag}$ and $\mathrm{Cl}$, alongside other contaminant elements that can be observed in the samples as a result of the preparation method (copper grid, carbon band, and platinum thin film which was deposited in order to increase the secondary electrons emitted from the surface of the specimen). This situation can be avoided by sample calcination before sample mounting.

As a complementary analysis in terms of shape, for nanoparticles biosynthesized by Raoultella planticola and Pantoea agglomerans, spherical nanoparticles can be observed (Figure 5). The obtained images confirmed that spherical particles were obtained that had a moderately rough surface and a diameter of approximately $60 \mathrm{~nm}$ on average. The size of the obtained particles was slightly different than that obtained from TEM and SEM 
measurements, which is expected considering that the geometry of the tip could lead to a change in the lateral dimensions of the nanoparticle, as in AFM. As a result, it is hard to determine the real diameter of the nanoparticles in an accurate manner. This technique was mainly used to provide images of the nanoparticles in terms of shape at an atomic level resolution by measuring the topography of the sample $[37,38]$. Figure 5 illustrates an AFM image representative of the silver chloride nanoparticles synthesized due to the bio-reduction activity of the microorganisms.

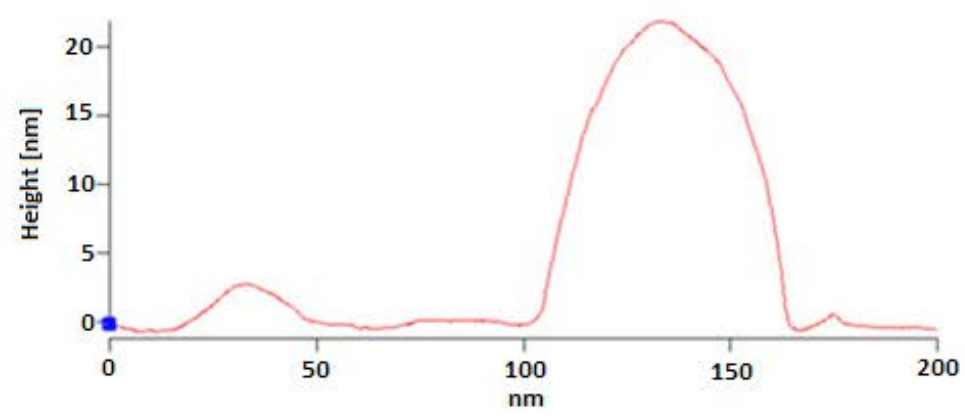

\section{D Ag/AgCl NP}
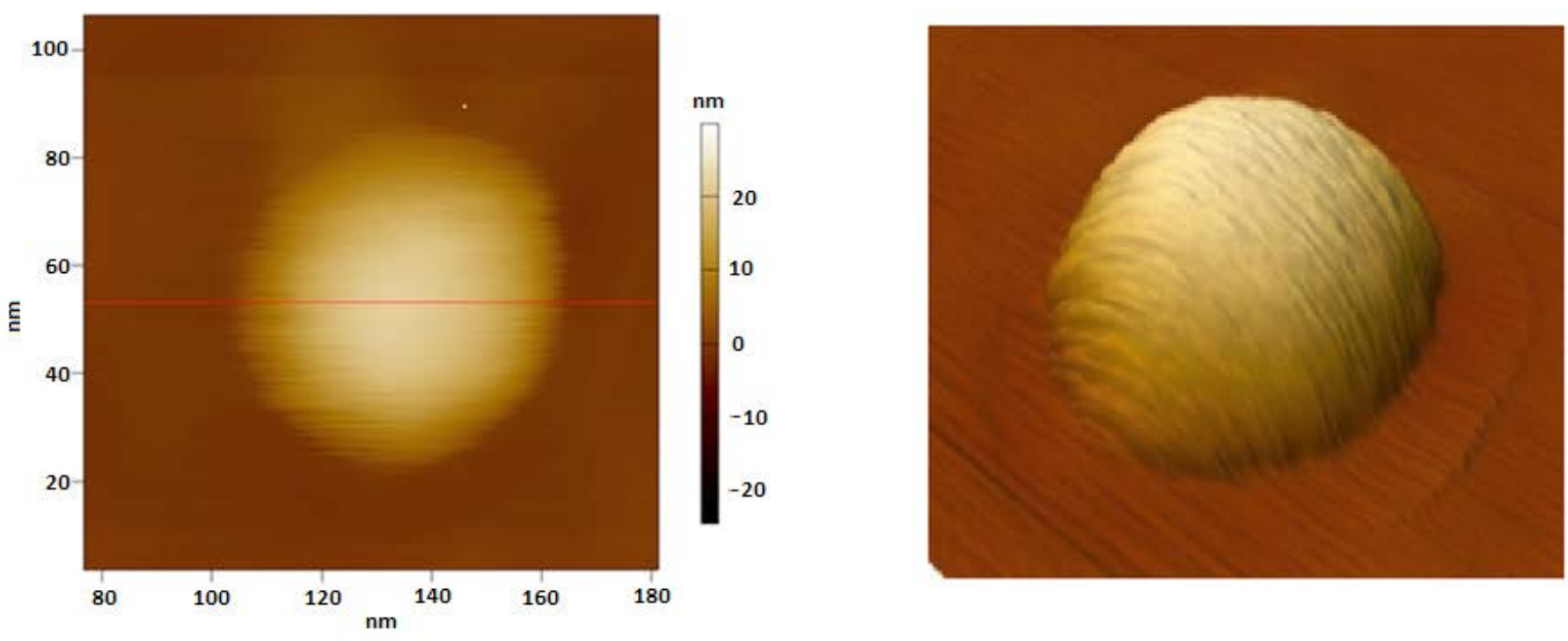

Figure 5. Cross section and three-dimensional (3D) representation of $\mathrm{AgCl} \mathrm{NPs}$.

Generally, smaller-sized nanoparticles are supposed to exhibit increased antimicrobial potential. Apart from the spherical shape of silver/silver chloride nanoparticles [7], different configurations have also been reported in the literature. $\mathrm{Ag} / \mathrm{AgCl}$ core-shell structure nanowires, nanocubes, and ellipsoids were synthesized using mostly chemical methods [36,39]. An in-depth analysis should be performed to see if the elongated shape is the result of the aggregation of two or more particles [34].

As the methods used with the characteristic process parameters (precursor concentration, temperature of the process, etc.) influence the structure of the synthesized nanoparticles, their shape and size also influence their capacity for use in various fields, such as their antimicrobial and photocatalytic activity [40].

The antimicrobial activities of metallic silver chloride nanoparticles against several bacterial strains have been reported elsewhere [21]. Other bio-reduced Ag/ AgCl NPs have demonstrated bacterial toxicity against several strains, including both Gram-positive (such as Staphylococcus aureus and Streptococcus pyrogens) and Gram-negative (such as Proteus vulgaris, Escherichia coli and Pseudomonas aeruginosa) pathogens [13,36,41]. 
In addition to the fact that the nanoparticles biosynthesized in this paper possess important antimicrobial activity against Staphylococcus aureus and Streptococcus pyogenes, the results showed that the nanoparticles obtained also possess antibacterial potential against other Gram-positive bacteria, such as Bacillus amyloliquefaciens, or Gram-negative bacteria, such as Salmonella.

Within the frame of this work, the antibiotic potential of $\mathrm{Ag} / \mathrm{AgCl}$ NPs was assessed against four species using the agar disc diffusion method. Figure 6 shows the variation of the inhibition zone diameter for discs containing $\mathrm{Ag} / \mathrm{AgCl} \mathrm{NPs} \mathrm{together} \mathrm{with} \mathrm{antibiotics}$ and the control antibiotic discs $(6 \mathrm{~mm})$. Compared to the chemical synthesis method, where possible chemical residues on nanoparticles may interact with biological systems, as well as the antibacterial effects of antibiotics, we manage to aid the synthesis of nanoparticles which are more biocompatible through the use of green methods [42]. It can be observed that two types of antibiotics (ciprofloxacin $5 \mu \mathrm{g}$ and erythromycin $15 \mu \mathrm{g}$ ) were used for the strain of Staphylococcus aureus to determine the synergism between these and $\mathrm{AgCl} \mathrm{NPs.} \mathrm{Two} \mathrm{types}$ of antibiotics were also used for Streptococcus pyogenes (vancomycin $30 \mu \mathrm{g}$ and erythromycin $15 \mu \mathrm{g}$ ). For Salmonella and Bacillus amyloliquefaciens, synergism was determined using only ciprofloxacin $5 \mu \mathrm{g}$. The antibacterial potential of silver chloride nanoparticles can also be observed in Figure 7, where the percentage increase in the antibacterial effect of antibiotics with $\mathrm{AgCl}$ NPs on the test strains is represented graphically (Equation (1)). Multiple bar graphs have been used to point out the stages where fold has increased. The highest value was noticed in the case when vancomycin was combined with nanoparticles synthesized by $R$. planticola against the test pathogen S. pyogenes, showing an increase in activity by $19.1 \%$. The nanoparticles synthesized by $P$. agglomerans showed the highest fold increase activity $(17.4 \%)$ in combination with erythromycin against $S$. aureus. A study conducted on the same subject by Baker et al. concluded that synergism between antibiotics and metallic nanoparticles led to increased antipathogenic activity [43].

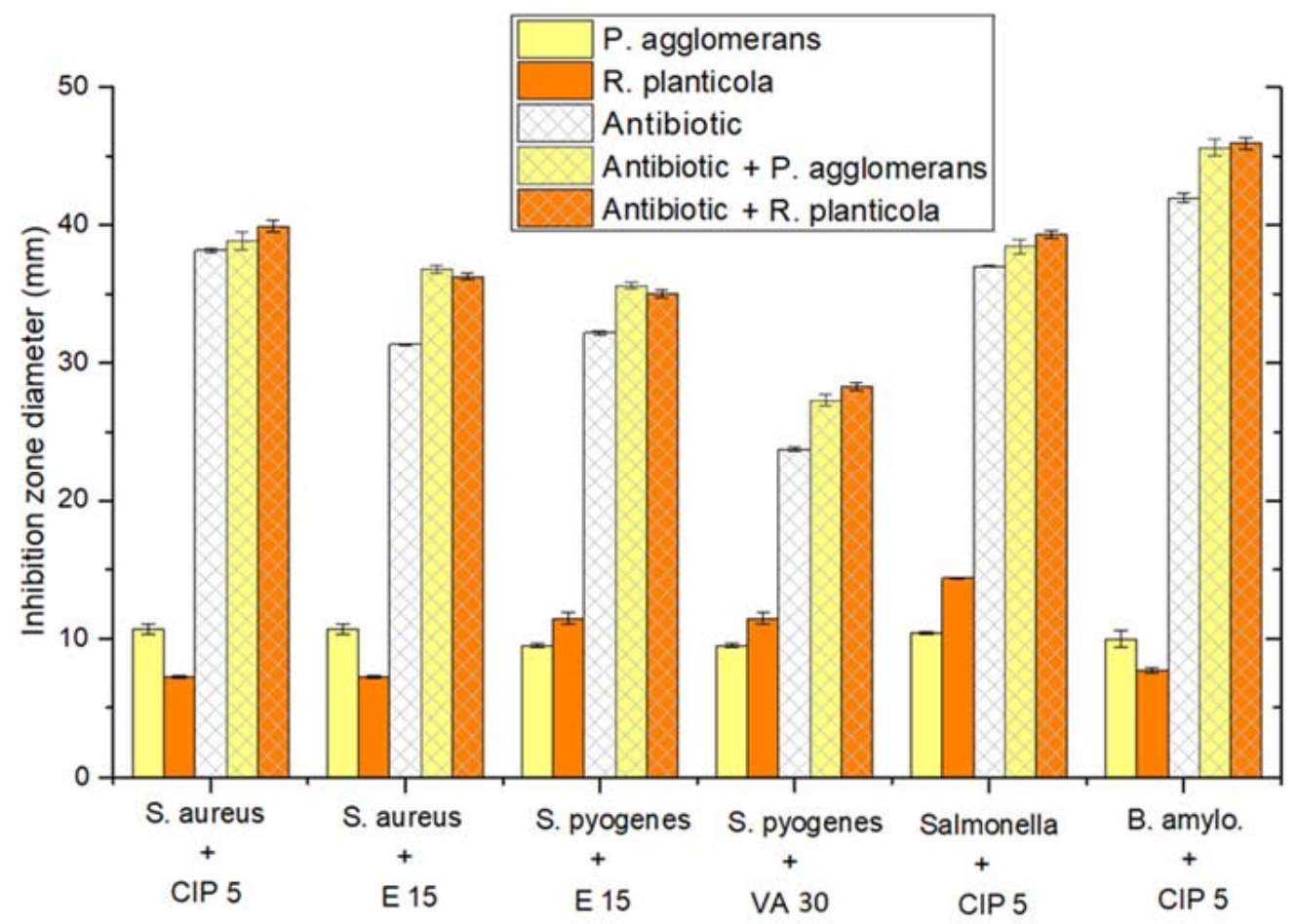

Figure 6. Diameter of inhibition zones for the bacterial strains tested with $\mathrm{Ag} / \mathrm{AgCl} \mathrm{NPs}$ disks, antibiotic disks, and the effect of synergism between $\mathrm{AgCl} \mathrm{NPs} \mathrm{+} \mathrm{antibiotics.} \mathrm{CIP:} \mathrm{ciprofloxacin;}$ E: erythromycin; VA: vancomycin. 


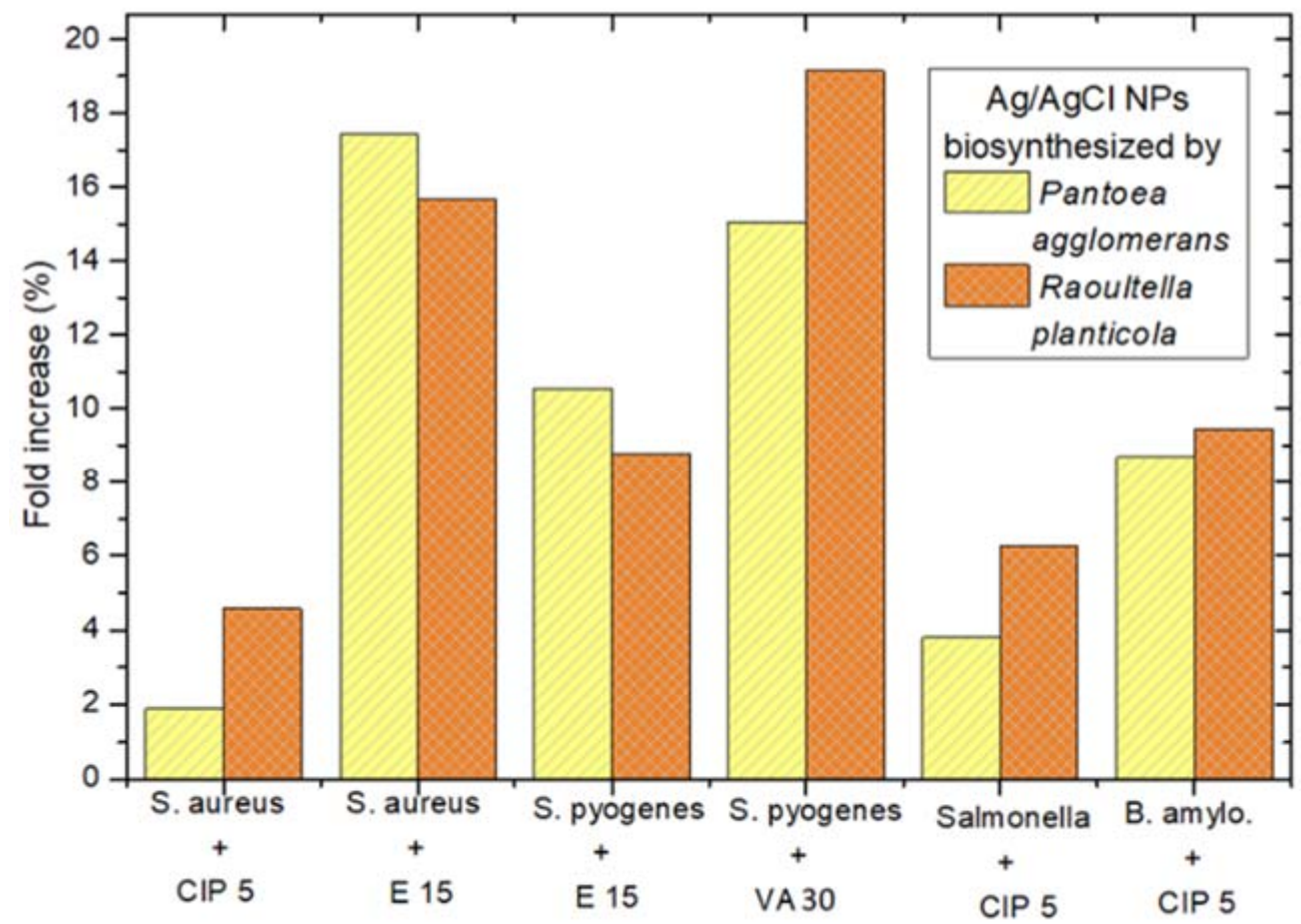

Figure 7. Percentage increase in the antibacterial effect of antibiotics with AgCl NPs against the tested strains.

The antimicrobial potential of silver and silver chloride nanoparticles tested through the disc diffusion method is showed photographically in Figure 8. After $24 \mathrm{~h}$ incubation, a difference in the inhibition diameter zone can be observed between the control samples (consisting of discs with ciprofloxacin $5 \mu \mathrm{g}$, vancomycin $30 \mu \mathrm{g}$, or erythromycin $15 \mu \mathrm{g}$ ) and antibiotics in combination with bio-reduced nanoparticles.

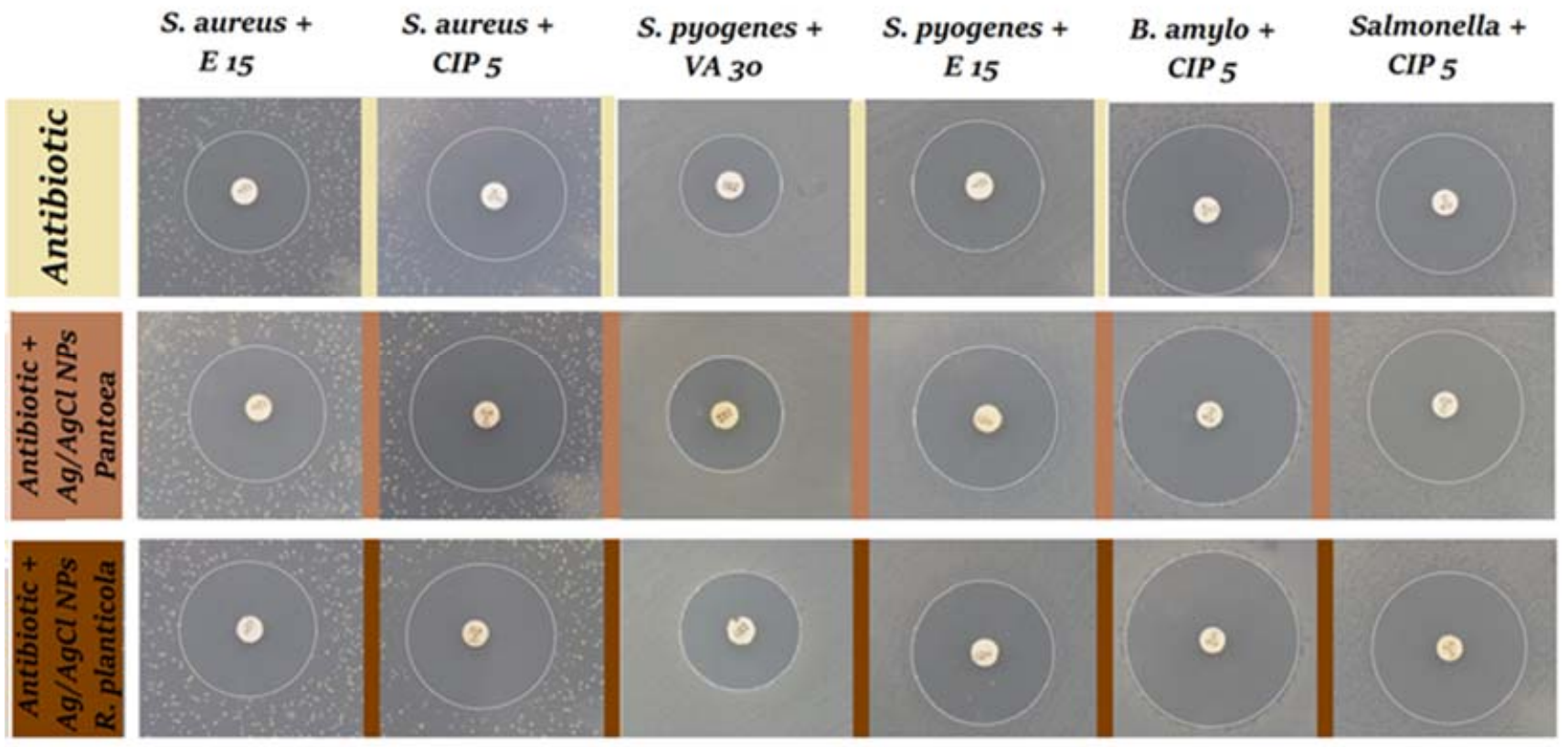

Figure 8. Images of the inhibition zone of Staphylococcus aureus, Streptococcus pyogenes, Salmonella, and Bacillus amyloliquefaciens in the presence of erythromycin, ciprofloxacin, and vancomycin, respectively. 
Synergism between antibiotics and nanoparticles was evident when using erythromycin in combination with $\mathrm{Ag} / \mathrm{AgCl}$ NPs synthesized by Raoultella planticola (activity was determined against $S$. aureus). The bio-reduced silver chloride nanoparticles were active in inhibiting the growth of S. aureus, S. pyogenes, Salmonella and B. amyloliquefaciens.

Thangudu and collaborators have reported the development of core-shell silver and silver chloride nanostructures with applications in nanomedicine. The obtained nanostructures have a good wound healing capacity and excellent therapeutic efficacy against methicillin-resistant Staphylococcus aureus infections in in vivo mice models [44]. The efficiency of many favorable technologies that use in vitro and in vivo assays has been proven by research conducted in the domain of antibacterial bio-coatings. The bacterial-derived coating has been shown to interfere with bacterial adhesion and with the initial phases of the biofilm formation in in vivo assays [45]. A critical overview of the effect of the potent antibacterial properties of silver-based coatings and nanomaterials on the inflammatory response has been published by Ninan and co-workers. They stated that the immunological response depends on many factors, including the size, shape, surface charge, and surface chemistry of the nanomaterial [46]. Therefore, further studies should be performed with the purpose of exploring the effect of silver on the immune system.

\section{Conclusions}

$\mathrm{Ag} / \mathrm{AgCl} \mathrm{NPs}$ were obtained by green synthesis. It has been shown that the cellfree culture supernatants of Pantoea agglomerans and Raoultella planticola are capable of synthesizing silver chloride nanoparticles. An essential condition that should be mentioned is that the precursor used was $\mathrm{AgNO}_{3}$, which is why it the composition of the growth media used for the microorganisms is imperative for the outcome. Brain Heart Infusion was used to grow the microorganisms as it contains sodium chloride, which can be considered as the core aspect that has led to the formation of silver chloride nanoparticles by reducing the $\mathrm{AgNO}_{3}$ precursor by Pantoea and Raoultella.

This cost-effective synthesis method is reinforced by the ecological process features. $\mathrm{Ag} / \mathrm{AgCl} \mathrm{NPs}$ were confirmed to have a high potential for antimicrobial activity. This experiments performed in this work prove the activity of silver chloride nanoparticles against microorganisms such as Staphylococcus aureus and Streptococcus pyogenes. It is strongly considered that biosynthesized nanoparticles will lead to new paths towards different biomedical applications as nanodrugs in the near future.

Author Contributions: Conceptualization, I.G.; methodology, I.G., C.C. and R.W.; investigation, I.G., C.C., R.W., J.K., and D.M.; writing—original draft preparation, I.G. and C.C.; writing-review and editing, I.G., J.K., and D.M.; supervision, J.K., and D.M. All authors have read and agreed to the published version of the manuscript.

Funding: This research received no external funding.

Institutional Review Board Statement: Not applicable.

Informed Consent Statement: Not applicable.

Data Availability Statement: The data presented in this study are available on request from the corresponding authors.

Conflicts of Interest: The authors declare no conflict of interest.

\section{References}

1. Shah, M.; Fawcett, D.; Sharma, S.; Tripathy, S.K.; Poinern, G.E. Green Synthesis of Metallic Nanoparticles via Biological Entities. J. Mater. 2015, 8, 7278-7308. [CrossRef] [PubMed]

2. Jeevanandam, J.; Chan, Y.S.; Danquah, M.K. Biosynthesis of Metal and Metal Oxide Nanoparticles. ChemBioEng Rev. 2016, 3, 55-67. [CrossRef]

3. Yeary, L.W.; Moon, J.W.; Love, L.J.; Thompson, J.R.; Rawn, C.J.; Phelps, T.J. Magnetic Properties of Biosynthesized Magnetite Nanoparticles. IEEE Trans. Magn. 2005, 41, 4384-4389. [CrossRef] 
4. Zhang, X.; Yan, S.; Tyagi, R.D.; Surampalli, R.Y. Synthesis of nanoparticles by microorganisms and their application in enhancing microbiological reaction rates. Chemosphere 2011, 82, 489-494. [CrossRef]

5. Reji, J.V.; Meenu, T.V.; Nair, S.K. A cost-effective method for green synthesis of silver nanoparticles using ocimum leaf extract. AIP Conf. Proc. 2020, 2263, 060004.

6. Sharma, V.K.; Yngard, R.A.; Lin, Y. Silver nanoparticles: Green synthesis and their antimicrobial activities. Adv. Colloid Interface Sci. 2009, 145, 83-96. [CrossRef]

7. Saeb, A.T.M.; Alshammari, A.S.; Al-Brahim, H.; Al-Rubeaan, K.A. Production of Silver Nanoparticles with Strong and Stable Antimicrobial Activity against Highly Pathogenic and Multidrug Resistant Bacteria. Sci. World J. 2014, 2014, 704708. [CrossRef]

8. Ahmed, A.-A.; Hamzah, H.; Maaroof, M. Analyzing formation of silver nanoparticles from the filamentous fungus Fusarium oxysporumand their antimicrobial activity. Turk J. Biol. 2018, 42, 54-62. [CrossRef]

9. Shivaji, S.; Madhu, S.; Singh, S. Extracellular synthesis of antibacterial silver nanoparticles using psychrophilicbacteria. Process. Biochem. 2011, 46, 1800-1807. [CrossRef]

10. Durán, N.; Nakazato, G.; Seabra, A.B. Antimicrobial activity of biogenic silver nanoparticles, and silver chloride nanoparticles: An overview and comments. Appl. Microbiol. Biotechnol. 2016, 100, 6555-6570. [CrossRef]

11. Dong, X.; Ji, X.; Wu, H.; Zhao, L.; Li, J.; Yang, W. Shape control of silver nanoparticles by stepwise citrate reduction. J. Phys. Chem. C 2009, 113, 6573-6576. [CrossRef]

12. Kabir, S.R.; Asaduzzaman, A.K.; Amin, R.; Haque, A.T.; Ghose, R.; Rahman, M.M.; Islam, J.; Amin, M.B.; Hasan, I.; Debnath, T. Zizyphus mauritiana Fruit Extract-Mediated Synthesized Silver/Silver Chloride Nanoparticles Retain Antimicrobial Activity and Induce Apoptosis in MCF-7 Cells through the Fas Pathway. ACS Omega 2020, 5, 20599-20608. [CrossRef] [PubMed]

13. Da Silva Ferreira, V.; ConzFerreira, M.E.; Lima, L.M.T.R.; Frases, S.; De Souza, W.; Sant'Anna, C. Green production of microalgaebased silver chloride nanoparticles with antimicrobial activity against pathogenic bacteria. Enzym. Microb. Technol. 2017, 97, 114-121. [CrossRef] [PubMed]

14. Hu, W.; Chen, S.; Li, X.; Shi, S.; Shen, W.; Zhang, X.; Wang, H. In situ synthesis of silver chloride nanoparticles into bacterial cellulose membranes. Mater. Sci. Eng. C 2009, 29, 1216-1219. [CrossRef]

15. Khodashenasa, B.; Ghorbani, H.R. Synthesis of silver nanoparticles with different shapes. Arab. J. Chem. 2019, 12, 1823-1838. [CrossRef]

16. Zhang, X.-F.; Liu, Z.-G.; Shen, W.; Gurunathan, S. Silver Nanoparticles: Synthesis, Characterization, Properties, Applications, and Therapeutic Approaches. Int. J. Mol. Sci. 2016, 17, 1534. [CrossRef]

17. Yusuf, M. Silver Nanoparticles: Synthesis and Applications. In Handbook of Ecomaterials; Martínez, L., Kharissova, O., Kharisov, B., Eds.; Springer: Cham, Switzerland, 2019.

18. Kang, Y.O.; Jung, J.-Y.; Cho, D.; Kwon, O.H.; Cheon, J.Y.; Park, W.H. Antimicrobial Silver Chloride Nanoparticles Stabilized with Chitosan Oligomer for the Healing of Burns. Materials 2016, 9, 215. [CrossRef]

19. Iravani, S.; Korbekandi, H.; Mirmohammadi, S.V.; Zolfaghari, B. Synthesis of silver nanoparticles: Chemical, physical and biological methods. Res. Pharm. Sci. 2014, 9, 385-406.

20. Tyagi, S. Effects of Ascorbic Acid and Phenolic Content Concentrations on Natural Reduction of Silver Ions from Plant Extracts. Res. Pharm. Sci. 2014, 9, 885-890. [CrossRef]

21. Durán, N.; Cuevas, R.; Cordi, L.; Rubilar, O.; Diez, M.C. Biogenic silver nanoparticles associated with silver chloride nanoparticles (Ag@AgCl) produced by laccase from Trametes versicolor. Springerplus 2014, 3, 645-651. [CrossRef]

22. Dhas, T.S.; Kumar, V.G.; Karthick, V.; Angel, K.J.; Govindaraju, K. Facile synthesis of silver chloride nanoparticles using marine alga and its antibacterial efficacy. Spectrochim. Acta A 2014, 120, 416-420. [CrossRef]

23. Eugenio, M.; Müller, N.; Frasés, S.; Almeida-Paes, R.; Maurício, L.; Lima, T.R.; Lemgruber, L.; Farina, M.; De Souza, W.; Sant'Anna, C. Yeast-derived biosynthesis of silver/silver chloride nanoparticles and their antiproliferative activity against bacteria. RSC Adv. 2016, 6, 9893-9904. [CrossRef]

24. Patil, M.P.; Seo, Y.B.; Kim, G.D. Morphological changes of bacterial cells upon exposure of silver-silver chloride nanoparticles synthesized using Agrimonia Pilosa. Microb. Pathog. 2018, 116, 84-90. [CrossRef] [PubMed]

25. Paulkumar, K.; Rajeshkumar, S.; Gnanajobitha, G.; Vanaja, M.; Malarkodi, C.; Annadurai, G. Biosynthesis of Silver Chloride Nanoparticles Using Bacillus subtilis MTCC 3053 and Assessment of Its Antifungal Activity. Int. Sch. Res. Not. 2013, 2013, 317963. [CrossRef]

26. Chandrappa, C.P.; Govindappa, M.; Chandrasekar, N.; Sarkar, S.; Ooha, S.; Channabasava, R. Endophytic synthesis of silver chloride nanoparticles from Penicillium sp. of Calophyllum apetalum. Adv. Nat. Sci. Nanosci. Nanotechnol. 2016, 7, 1-5. [CrossRef]

27. Ghiuță, I.; Cristea, D.; Wenkert, R.; Munteanu, D. Green synthesis of silver chloride nanoparticles using Rhodotorula Mucilaginosa. Mater. Res. Proc. 2018, 8, 28-34.

28. Ghiuță, I.; Cristea, D.; Croitoru, C.; Kost, J.; Wenkert, R.; Vyrides, I.; Anayiotos, A.; Munteanu, D. Characterization and antimicrobial activity of silver nanoparticles, biosynthesized using Bacillus species. Appl. Surf. Sci. 2018, 438, 66-73. [CrossRef]

29. Ovais, M.; Khalil, A.T.; Ayaz, M.; Ahmad, I.; Nethi, S.K.; Mukherjee, S. Biosynthesis of Metal Nanoparticles via Microbial Enzymes: A Mechanistic Approach. Int. J. Mol. Sci. 2018, 19, 4100. [CrossRef]

30. Deljou, A.; Goudarzi, S. Green Extracellular Synthesis of the Silver Nanoparticles Using Thermophilic Bacillus Sp. AZ1 and its Antimicrobial Activity Against Several Human Pathogenetic Bacteria. Iran J. Biotechnol. 2016, 54, 25-32. [CrossRef] 
31. Patra, J.K.; Baek, K.-H. Green synthesis of silver chloride nanoparticles using Prunus persica L. outer peel extract and investigation of antibacterial, anticandidal, antioxidant potential. Green Chem. Lett. Rev. 2016, 9, 132-142. [CrossRef]

32. Liu, Y.; Tan, J.; Thomas, A.; Ou-Yang, D.; Muzykantov, V.R. The shape of things to come: Importance of design in nanotechnology for drug delivery. Ther. Deliv. 2012, 3, 181-194. [CrossRef]

33. Choi, O.; Deng, K.K.; Kim, N.J.; Ross, L., Jr.; Surampalli, R.Y.; Hu, Z. The inhibitory effects of silver nanoparticles, silver ions, and silver chloride colloids on microbial growth. Water Res. 2008, 42, 3066-3074. [CrossRef]

34. Das, M.R.; Sarma, R.K.; Saikia, R.; Kale, V.S.; Shelke, M.V.; Sengupta, P. Synthesis of silver nanoparticles in an aqueous suspension of graphene oxide sheets and its antimicrobial activity. Colloids Surf. B 2011, 83, 16-22. [CrossRef] [PubMed]

35. Ider, M.; Abderrafi, K.; Eddahbi, A.; Ouaskit, S.; Kassiba, A. Silver Metallic Nanoparticles with Surface Plasmon Resonance: Synthesis and Characterizations. J. Clust. Sci. 2017, 28, 1051-1069. [CrossRef]

36. Trinh, N.D.; Nguyen, T.T.B.; Nguyen, T.H. Preparation and characterization of silver chloride nanoparticles as an antibacterial agent. Adv. Nat. Sci. Nanosci. Nanotechnol. 2015, 6, 1-6. [CrossRef]

37. Delvallée, A.; Feltin, N.; Ducourtieux, S.; Trabelsi, M.; Hochepied, J.-F. Comparison of nanoparticle diameter measurements by Atomic Force Microscopy and Scanning Electron Microscopy. In Proceedings of the 16th International Congress of Metrology, Paris, France, 7-10 October 2013; p. 6.

38. Lachowicz, D.; Kaczynska, A.; Bodzon-Kulakowska, A.; Karewicz, A.; Wirecka, R.; Szuwarzyński, M.; Zapotoczny, S. Coacervate Thermoresponsive Polysaccharide Nanoparticles as Delivery System for Piroxicam. Int. J. Mol. Sci. 2020, 21, 9664. [CrossRef]

39. Qin, Y.; Cui, Y.; Tian, Z.; Wu, Y.; Li, Y. Synthesis of AG@AgCl Core-Shell Structure Nanowires and Its Photocatalytic Oxidation of Arsenic (III) Under Visible Light. Nanoscale Res. Lett. 2017, 12, 1-10. [CrossRef]

40. Pal, S.; Tak, Y.K.; Song, J.M. Does the Antibacterial Activity of Silver Nanoparticles Depend on the Shape of the Nanoparticle? A Study of the Gram-Negative Bacterium Escherichia coli. Appl. Environ. Microbiol. 2007, 73, 1712-1720. [CrossRef]

41. Gopinath, V.; Priyadarshini, S.; Meera Priyadharsshini, N.; Pandian, K.; Velusamy, P. Biogenic synthesis of antibacterial silver chloride nanoparticles using leaf extracts of Cissus quadrangularis Linn. Mater. Lett. 2013, 91, 224-227. [CrossRef]

42. Shahverdi, A.R.; Fakhimi, A.; Shahverdi, H.R.; Minaian, S. Synthesis and effect of silver nanoparticles on the antibacterial activity of different antibiotics against Staphylococcus aureus and Escherichia coli. Nanomed. Nanotechnol. Biol. Med. 2007, 3, 168-171. [CrossRef] [PubMed]

43. Bakera, S.; Pashaa, A.; Satish, S. Biogenic nanoparticles bearing antibacterial activity and their synergistic effect with broad spectrum antibiotics: Emerging strategy to combat drug resistant pathogens. Saudi Pharm. J. 2017, 25, 44-51. [CrossRef]

44. Thangudu, S.; Kulkarni, S.S.; Raviraj, V.; Chiang, C.-S.; Hwang, K.C. Photosensitized Reactive Chlorine Species-Mediated Therapeutic Destruction of Drug-Resistant Bacteria using Plasmonic Core-Shell Ag@AgCl Nanocubes as External Nanomedicines. Nanoscale 2020, 12, 12970-12984. [CrossRef]

45. Gallo, J.; Holinka, M.; Moucha, C.S. Antibacterial Surface Treatment for Orthopaedic Implants. Int. J. Mol. Sci. 2014, 15, 13849-13880. [CrossRef] [PubMed]

46. Ninan, N.; Goswami, N.; Vasilev, K. The Impact of Engineered Silver Nanomaterials on the Immune System. Nanomaterials 2020, 10, 967. [CrossRef] [PubMed] 